\title{
Identification of glycosylated marker proteins of epithelial polarity in MDCK cells by homology driven proteomics Joachim Füllekrug*1,2, Anna Shevchenko ${ }^{1}$, Andrej Shevchenko ${ }^{1}$ and Kai Simons ${ }^{1}$
}

\author{
Address: ${ }^{1}$ Max-Planck-Institute of Molecular Cell Biology and Genetics, Dresden, Germany and ${ }^{2}$ University of Heidelberg, Internal Medicine IV, \\ Molecular Cell Biology Group, Im Neuenheimer Feld 345, 69120 Heidelberg, Germany \\ Email: Joachim Füllekrug* - Joachim.Fuellekrug@med.uni-heidelberg.de; Anna Shevchenko - ashevche@mpi-cbg.de; \\ Andrej Shevchenko - shevchenko@mpi-cbg.de; Kai Simons - simons@mpi-cbg.de \\ * Corresponding author
}

Published: 13 March 2006

BMC Biochemistry2006, 7:8 doi:10.1186/147|-2091-7-8

This article is available from: http://www.biomedcentral.com//47|-209|/7/8

(c) 2006Füllekrug et al; licensee BioMed Central Ltd.

This is an Open Access article distributed under the terms of the Creative Commons Attribution License (http://creativecommons.org/licenses/by/2.0), which permits unrestricted use, distribution, and reproduction in any medium, provided the original work is properly cited.
Received: 22 November 2005

Accepted: 13 March 2006

\begin{abstract}
Background: MDCK cells derived from canine kidney are an important experimental model system for investigating epithelial polarity in mammalian cells. Monoclonal antibodies against apical gp I 4 and basolateral p58 have served as important tools in these studies. However, the molecular identity of these membrane glycoproteins has not been known.

Results: We have identified the sialoglycoprotein gpll4 as a dog homologue of the carcinoembryonic antigen-related cell adhesion molecule (CEACAM) family. Gp I 4 was enriched from tissue culture cells by subcellular fractionation and immunoaffinity chromatography. The identification was based on tandem mass spectrometry and homology based proteomics. In addition, the $\mathrm{p} 58$ basolateral marker glycoprotein was found to be the $\beta$ subunit of $\mathrm{Na}^{+} \mathrm{K}^{+}$-ATPase.

Conclusion: Gpll4 has been characterized previously regarding glycosylation dependent trafficking and lipid raft association. The identification as a member of the canine CEACAM family will enable synergy between the fields of epithelial cell biology and other research areas. Our approach exemplifies how membrane proteins can be identified from species with unsequenced genomes by homology based proteomics. This approach is applicable to any model system.
\end{abstract}

\section{Background}

Madin-Darby canine kidney (MDCK) cells are the best established mammalian model for studying epithelial cell biology. MDCK cells differentiate into polarized cells within a few days when grown on semi-permeable filter supports. The cells form an epithelial monolayer, with tight junctions separating an apical surface from a basolateral membrane facing the filter support and neighbouring cells. Both surfaces have a unique composition of proteins and lipids $[1,2]$. Newly synthesized secretory pro- teins are sorted in the trans-Golgi network and from there transported to the apical and basolateral surfaces. Sorting of proteins to the basolateral surface often relies on proteinaceous signals in cytoplasmically exposed domains of the protein. Association with lipid rafts and glycosylation have been proposed to be involved in apical targeting [3].

As marker proteins of the apical and basolateral plasma membrane of MDCK cells we have previously raised monoclonal antibodies recognizing two membrane glycopro- 


\section{A}
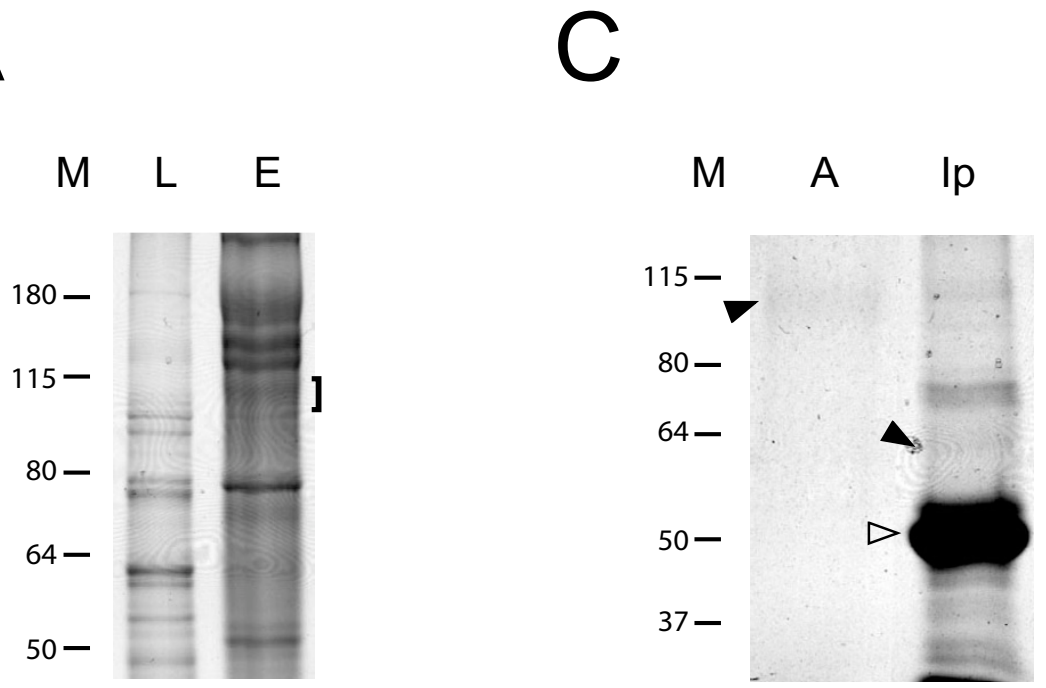

B

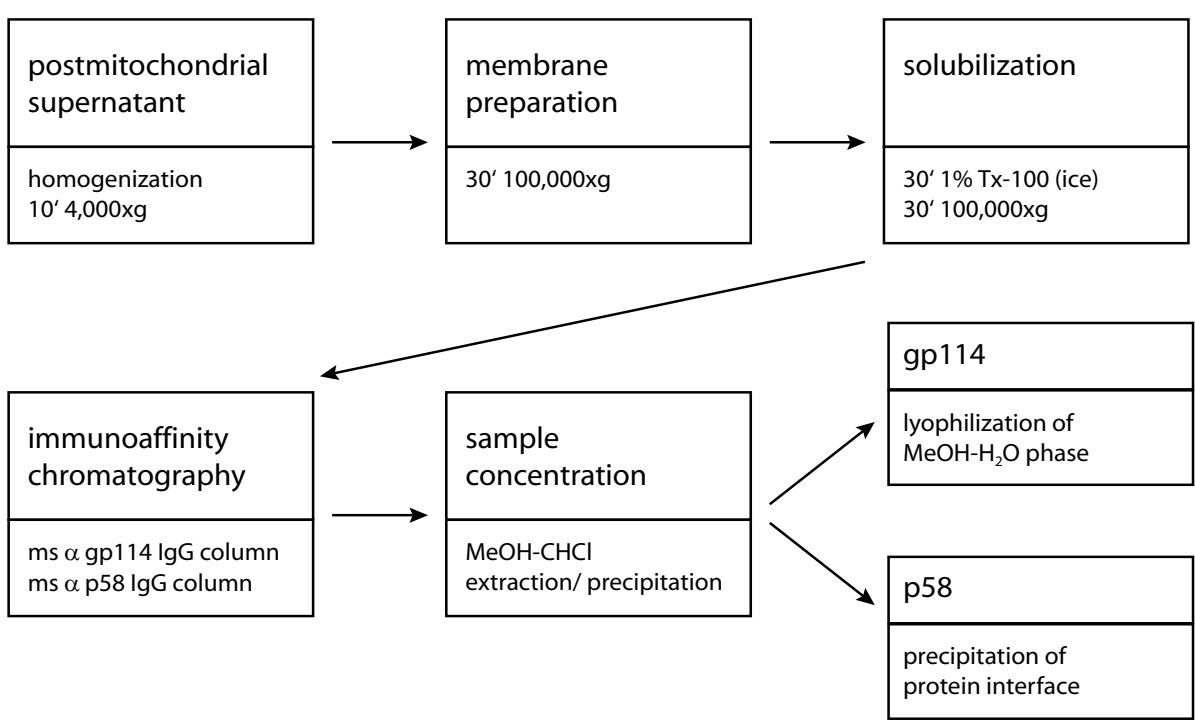

Figure I

A. WGA lectin affinity chromatography of MDCK cell membrane proteins. Bound proteins were eluted with $0.3 \mathrm{MN}$ acetylglucosamine, and stained by Coomassie blue after gel electrophoresis. L: aliquot of loaded protein preparation. E: eluted protein pattern (bracket indicates II $4 \mathrm{kDa}$ region). B. Flow chart for the purification of gp I I4. MDCK cell membranes were recovered by high-speed centrifugation from a postmitochondrial supernatant and partially solubilized by treatment with the non-ionic detergent Triton $X-100$ on ice. Soluble proteins were applied to immunoaffinity columns, and the eluted fractions concentrated by methanol-chloroform extraction-precipitation. GpI I 4 did not accumulate at the "protein" interface between aqueous and lipid phase but stayed in the hydrophilic supernatant. C. Enrichment of gp I I4. Lane I (A) corresponds to the methanolic phase after chloroform-methanol extraction of eluted proteins from the gP I I4 immunoaffinity column. Gp I I4 (arrowhead) is only weakly stained by Coomassie solution. Lane 2 (Ip) contains deglycosylated gp I 4 (arrowhead) after immunoprecipitation which was confirmed by Western blotting (not shown). The heavy chain of gP I I I IgG is indicated by a white arrowhead. 
teins. The apical marker protein gp114 is a highly glycosylated integral membrane protein with an apparent molecular weight of $114 \mathrm{kDa}[4,5]$. The basolateral marker protein has been termed p58 according to apparent molecular weight. In subconfluent monolayers of MDCK cells, p58 localizes to both the basolateral and the apical surface, but later disappears from the apical surface, concomitantly with the development of a tight monolayer [4].

The proteomic identification of membrane proteins of MDCK cells, especially when highly glycosylated, still presents a considerable challenge. First, it is rather difficult to isolate these proteins in sufficient amounts. Second, the canine genome is only partially available and EST sequences do not adequately cover its proteome. Conventional methods of database searching rely heavily on matching masses of intact peptides (peptide mass mapping) or their fragments (tandem mass spectrometry) to the corresponding masses obtained by in silico processing of protein sequences from database entries [6]. Stringent matching of computed and measured masses increases the specificity and the speed of database searching considerably, yet restricts the reach of proteomics methodologies down to a handful of favourably covered model species [7]. Recently developed methods of mass spectrometry driven sequence similarity searches $[8,9]$ utilize redundant, degenerate and partially inaccurate peptide sequences, produced by de novo interpretation of tandem mass spectra and are capable of identifying distant homologues of known proteins from phylogenetically distant organisms [10].

In this work we applied immunoaffinity chromatography to enrich the heavily glycosylated membrane proteins gp114 and p58 and identify them by tandem mass spectrometry and homology driven proteomics.

\section{Results and discussion}

Enrichment of gp / /4 by immunoaffinity chromatography

Our first approach was based on the glycoprotein properties of gp114 [5]. A membrane fraction of MDCK cells was enriched for glycoproteins by lectin affinity chromatography using wheat germ agglutinin. The $114 \mathrm{kDa}$ region of the gel electrophoresis pattern (Figure 1a) was analyzed by mass spectrometry. Six peptides matched canine intercellular adhesion molecule 1 (ICAM-1). Other proteins identified were not apical proteins $(\alpha 2-, \beta 1$-integrins, CD44, LAMP-2). A few peptides from low abundant spectra could not be assigned to any protein. Antibodies against dog ICAM-1 immunoprecipitated a $114 \mathrm{kDa}$ protein, but this protein was not recognized by antibodies against gp114 (not shown). Therefore we concluded that gp114 is a protein different from ICAM-1.
Immunoaffinity columns established with mouse anti gp114 IgG were used for a more efficient enrichment of gp114. Detergent soluble membrane protein fractions were applied to immunoaffinity columns, and the eluted fractions concentrated by methanol-chloroform extraction-precipitation. Surprisingly, gp114 did not partition with other proteins, but remained in the aqueous phase, probably due to its high glycosylation (see the flow chart of the purification of gp114, Figure 1b). Gel electrophoresis followed by Coomassie blue staining revealed a single faint band corresponding to gp114 (Figure 1c). In parallel, gp114 was first immunoprecipitated and then enzymatically deglycosylated since we anticipated that the high amount of glycosylation might affect the efficiency of tryptic digestion prior to the analysis by mass spectrometry (Figure 1c).

\section{Identification of gp/ I 4 by mass spectrometry}

The MALDI TOF spectrum of a tryptic digest of the gp114 band contained only two peptide signals, which is a surprisingly low number for a protein of this size (Figure 2, inset). Since MALDI and electrospray spectra acquired from the same digest usually demonstrate different peptide profiles [11], the digest was further investigated by nanoelectrospray tandem mass spectrometry (Figure 2). The Mascot database search with uninterpreted tandem mass spectra gave only three matches to immunoglobulin peptides, although 40 precursor ions were fragmented. The major peptide peaks in the spectrum remained unassigned. Therefore the unmatched tandem mass spectra were manually interpreted de novo by considering mass differences between adjacent peaks of fragment ions (Figure 3). This approach only rendered low confidence amino acid sequences since it is not known if the considered ions indeed belong to the same fragment series [12]. Furthermore, spectra from multiply charged precursor ions contained non-overlapping fragment series with different charge states, which did not cover the complete peptide sequence. Therefore the interpretation of each spectrum produced several inaccurate, partially redundant and incomplete peptide sequence proposals (Table 1). We then merged peptide sequence candidates obtained by the interpretation of all good quality tandem mass spectra into a single search string and employed the mass spectrometry-driven BLAST (MS BLAST) protocol for the identification of proteins by sequence similarity searching $[9,10]$. The database search confidently hit proteins of the carcinoembryonic antigen (CEA) protein family (Table 1 ). The table shows only the first protein homologue of the database search, carcinoembryonic antigen-related cell adhesion molecule 8 (CEACAM8), but other CEA family proteins gave the same alignment with an identical score. Remarkably, not a single alignment covered the corresponding sequence completely. The conservation of gp114 across species is apparently not sufficient for an 


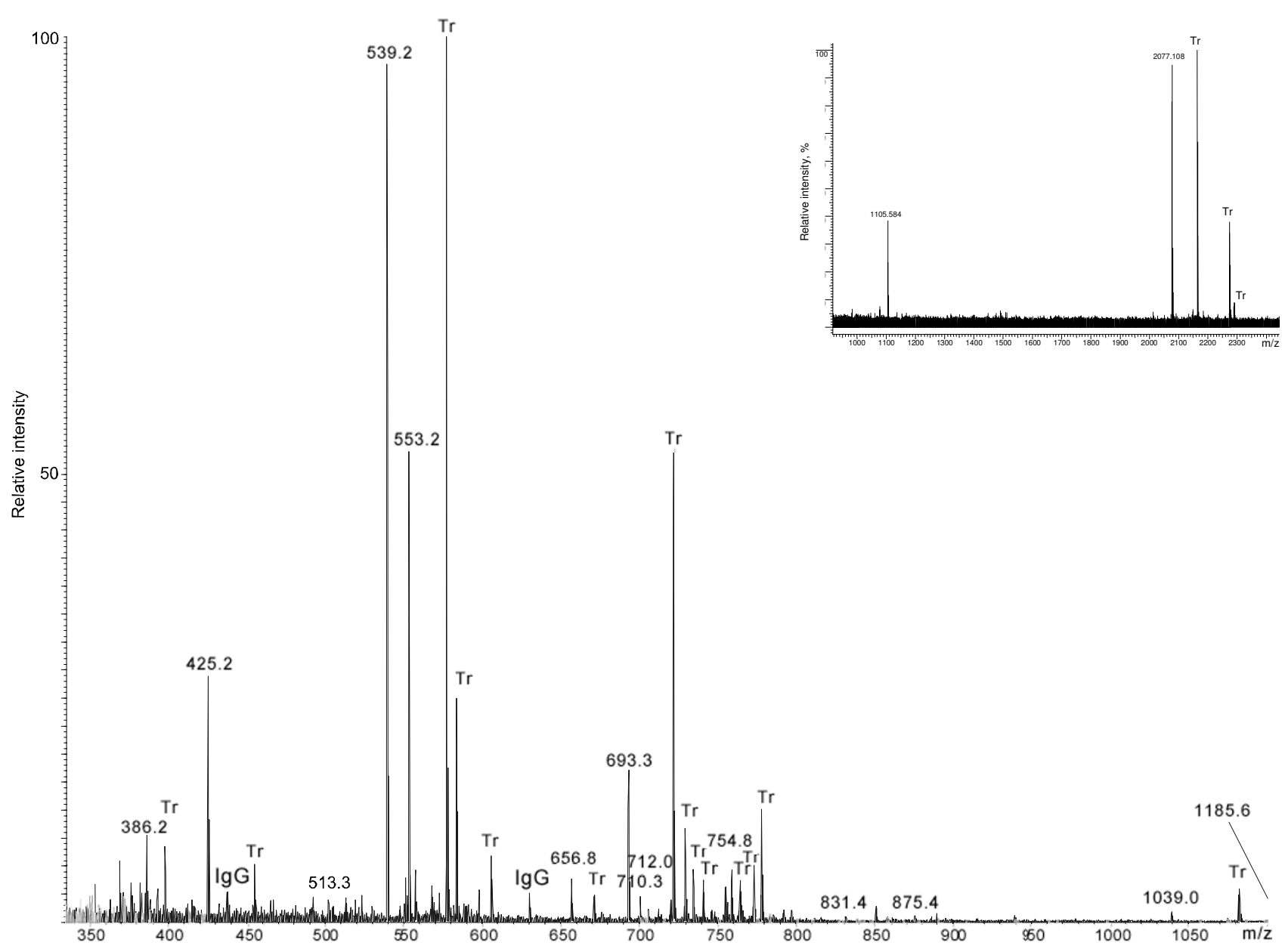

\section{Figure 2}

Nanoelectrospray spectrum of in-gel tryptic digest of gp I 4. Peaks labeled with Tr originated from the autolysis of trypsin; peaks labeled with IgG were identified as tryptic peptides from IgG antibodies by Mascot searches. Tandem mass spectra of other peaks were not matched by Mascot and were subjected to de novo interpretation (Figure 3). Inset: MALDI TOF peptide mass map of the tryptic digest of the gP I 4 band obtained from the gel shown in figure Ic, lane A. Deglycosylated gP I I 4 gave the same spectrum (not shown). Peaks of autolysis products of trypsin labeled with Tr. Peaks of peptides originating from gP I 4 are designated with their $\mathrm{m} / \mathrm{z}$.

identification by cross-species matching of acquired tandem mass spectra matching using Mascot software [13].

\section{In silico analysis of gp I / 4}

The CEA protein family consists of two separate branches, the membrane associated CEACAM proteins and the soluble pregnancy-specific glycoproteins (PSG). The CEACAM proteins are extensively spliced yielding numerous isoforms. In addition, some CEACAM proteins are modified to include a glycophosphatidylinositol (GPI) anchor instead of a transmembrane domain (reviewed in $[14,15])$. Gp114 is an integral membrane protein ([16] and references therein) and belongs therefore to the CEACAM subgroup.
MS BLAST searches could only be performed against a protein database. Once gp114 had been identified as a canine CEACAM protein, we used the human CEACAM1 nucleotide sequence to search for homologous genes. One genomic sequence (FE8, see Methods for details) contained an exon sequence homologous to human CEACAM1. Five of the sequenced peptides could be matched exactly to this translated exon sequence (Table 1). Other canine genomic sequences homologous to human CEACAM1 were either identical to FE8 or did not match the sequenced peptides. Thus identical peptides identified in the dog genome validated the sequence similarity identification by MS BLAST. One of the peptides (\#6) had also been detected in our first analysis of lectin 
bound $114 \mathrm{kDa}$ proteins, but could not be assigned at that time. This confirmed that gp114 was indeed present in the lectin bound $114 \mathrm{kDa}$ fraction, but could not be identified on the basis of a single peptide sequence.

While this manuscript was under evaluation, the canine genome became publicly available [17]. A tentative amino acid sequence was obtained (see Methods for details) which was significantly similar to human CEACAM family proteins $1,5,8$ and 6. CEACAM 5, 8 and 6 are GPI anchored proteins which have been reported to be expressed in humans only [14]. Furthermore, the predicted molecular weights of the mature proteins (without $\mathrm{N}$-glycans) are $54 \mathrm{kDa}$ for human CEACAM1, $71 \mathrm{kDa}$ for CEACAM 5 and $32 \mathrm{kDa}$ for CEACAM 8 and 6 . Only the molecular weight of human CEACAM1 corresponds reasonably to the size of deglycosylated gp114 [18]. Deglycosylated gp114 (Figure 1c) gave the same two characteristic fragments as the untreated protein by MALDI TOF analysis (not shown). Other names for CEACAM1 are biliary glycoprotein, BGP1, TM-CEA and CD66a [19]. In summary, gp114 is a dog CEACAM protein, most likely CEACAM1.

\section{Properties of canine CEACAM/gp I / 4}

Apical sorting of gp114/canine CEACAM occurs directly to the surface with a half time of 45 minutes [16]. The glycans are of the N-glycosylated complex type containing sialic acid, contributing about half of the apparent molecular weight of gp114 $[5,18]$. However, in MDCK-RCA cells deficient in terminal glycosylation due to an inactivated UDP-galactose transporter [20,21], gp114 was missorted to the basolateral surface, whereas targeting of other apical proteins was not affected. Furthermore, endocytosis of gp114 is also highly increased in these cells compared to a very slow internalization in MDCK wild type cells [18]. Independently, gp114 was identified as a major protein undergoing bidirectional transcytosis in MDCK-RCA cells [22]. Antibody crosslinking shows that gp114 coclusters with lipid raft associated proteins in the apical membrane of MDCK cells [23].

Lipid raft microdomain association and glycosylation dependent trafficking (basolateral missorting, endocytosis, transcytosis) have not been reported for CEACAM proteins so far. Reversible association with lipid microdomains has been put forward as a core mechanism in the regulation of signal transduction at the plasma membrane [24]. Our identification enables the integration of the data obtained for gp114 with the characterization of CEACAM proteins from other approaches.

\section{Identification of $\mathrm{p} 58$}

The p58 protein was enriched by immunoaffinity chromatography, similarly to gp 114 . The trypsin digested band of p58 was identified as the $\beta$-chain of canine $\mathrm{Na}^{+} \mathrm{K}^{+}$-ATPase by peptide mass fingerprinting. 15 peptides were matched to the masses of corresponding tryptic peptides with better than $100 \mathrm{ppm}$ mass tolerance. The MOWSE score of 143 exceeded the significance threshold of 72 and thus the identification was considered confident.

The $\beta$-subunit of $\mathrm{Na}^{+} \mathrm{K}^{+}$-ATPase contains three $\mathrm{N}$-linked glycans, which is consistent with the apparent molecular weight of the expressed protein. The association of the $\beta$ subunit with the $\alpha$-subunit is required for the enzyme complex to reach the plasma membrane (for a review, see [25]). The polarized expression of $\mathrm{Na}^{+} \mathrm{K}^{+}$-ATPase in epithelia depends on the association of $\beta$-subunits from neighbouring cells [26]. The molecular weight of the $\alpha$ subunit corresponds to the protein coprecipitating with p58 antibodies under non-denaturing conditions (not shown). $\mathrm{Na}^{+} \mathrm{K}^{+}$-ATPase has also been used in other cell systems as a basolateral marker protein.

\section{MS identification of proteins from organisms with unsequenced genomes}

Mass spectrometry driven sequence similarity searches now make it possible to characterize proteins from model organisms with unsequenced genomes by their similarity to already available sequences. Computational simulations suggested that almost all proteins within mammalian phylogenetic lineage could be identified by MS BLAST sequence similarity searches using 10 sequenced tryptic peptides, which is a rather frequent outcome of tandem mass spectrometric experiments [10]. Importantly, the method imposes rather loose requirements on the quality of peptide sequences and thus paves the way to complete automation of the analytical routine. Mass spectrometric characterization of unknown proteins can be performed in a layered approach $[7,27]$ i.e. conventional proteomics methods could be applied first to identify highly conserved proteins that share identical peptide sequences with their known homologues, and sequence similarity searches would only be applied to a selection of non-conserved proteins once the conventional methods failed. Thus we might anticipate that the scope of proteomics methods will be able to support biochemical research in any vertebrate model.

\section{Conclusion}

The apical marker glycoprotein gp114 has been enriched from tissue culture cells and identified by tandem mass spectrometry as canine carcinoembryonic antigen-related cell adhesion molecule (CEACAM). We exemplify the difficulties associated with identifying glycoproteins from model systems without sequenced genomes, and how to overcome them. The general strategy provides a frame- 
* Precursor ion $\mathrm{m} / \mathrm{z} 656.8, \mathrm{z}=4$

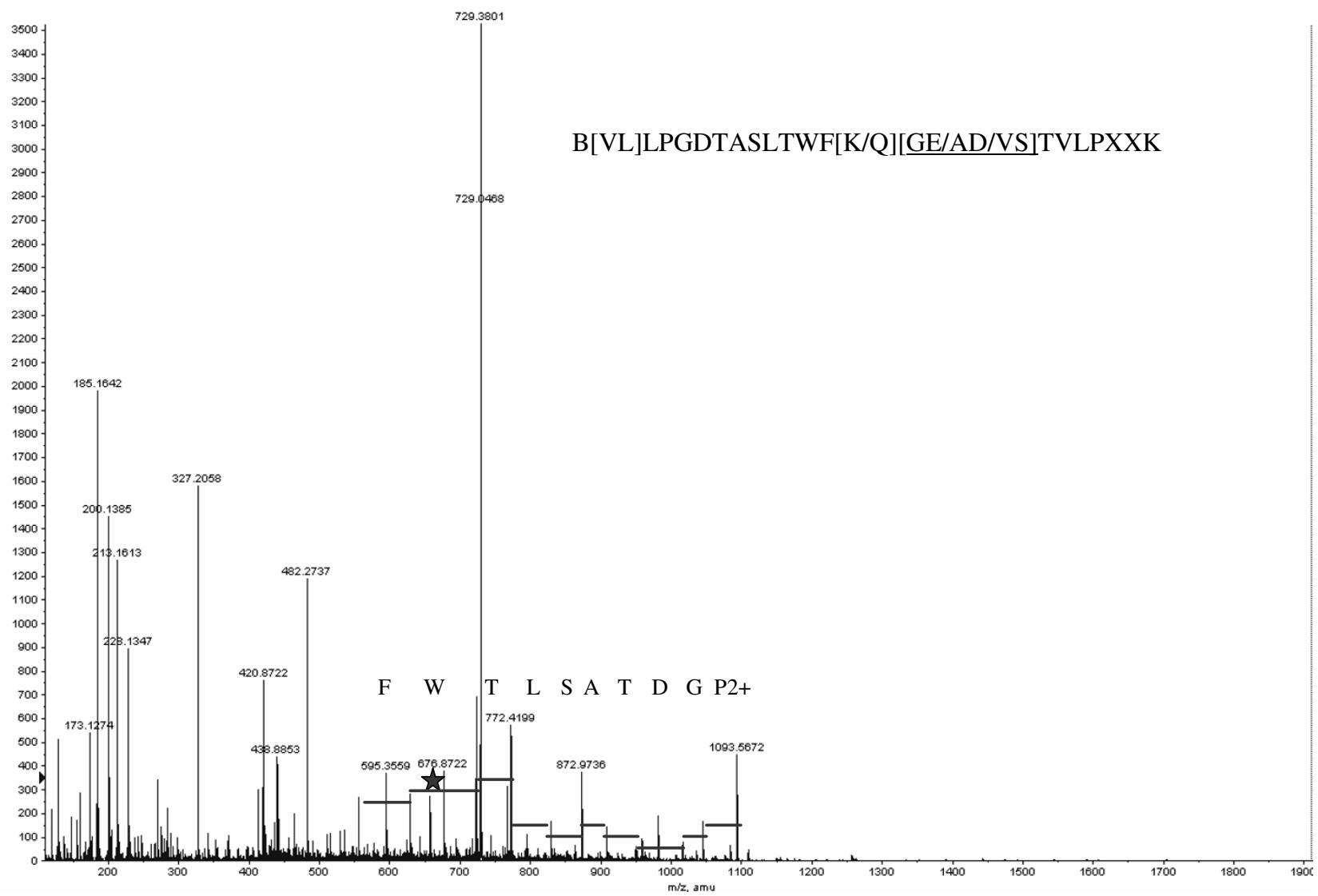

\section{Figure 3}

Tandem mass spectrum of a precursor ion with $\mathrm{m} / \mathrm{z} 656.8$ and charge +4 (the charge was determined from mass difference between its isotopic peaks). The precursor ion is labeled with an asterisk. The spectrum was partially interpreted by considering precise mass differences between the adjacent fragment ions. Doubly charged fragment series rendered the sequence PGDTASLTWF which was further extended toward the $\mathrm{N}$-terminus using very low abundant ions in the $\mathrm{m} / \mathrm{z}$ range $>\mathrm{I} I 00$ (not shown), but the sequence of the two $\mathrm{N}$-terminal amino acid residues remained ambiguous (VL or LV). It was possible to determine the C-terminal amino acid $(\mathrm{K})$ and a short sequence stretch (TVLP) spaced from the C-terminal lysine by two or three unknown amino acid residues $(X)$. Bridging between the sequence stretches PGDTASLTWF and TVLP could have been achieved by one of the three isobaric combination of amino acid residues, and the order of amino acid residues remained unknown. Hence the peptide might contain the sequence WF-QGET-VL, or WF-QEGT-VL, or WF-QADT-VL, or WF-QDATVL..., etc.

work which should be useful for many related approaches.

Known properties of gp114 such as glycosylation dependent transcytosis and association with lipid microdomains involved in signal transduction can now be integrated with the knowledge about CEACAM proteins obtained by different approaches.

\section{Methods}

IgG-protein $\mathbf{G}$ sepharose columns

A membrane fraction from dog intestine was used for generation of monoclonal antibodies 4.6.5a (gp114) and 6.23.3 (p58) [4]. Hybridoma cells 4.6.5a and 6.23.3 were grown in serum-free HyQ SFX-MAb medium (HyClone, Logan, Utah) for two weeks. Supernatants were clarified by sequential centrifugation at $200 \times \mathrm{g}$ and $10,000 \times \mathrm{g}$, 
Table I: Peptide sequences of gp I I 4 derived from MS/MS spectra. Peptide sequences from gp I I 4 produced by the interpretation of MS/MS spectra and MS BLAST alignments with corresponding peptides. $X$ are unidentified amino acid residues, $L$ stands for both Leu and Ile residues; B stands for a generic trypsin cleavage site (Arg or Lys); sequences in brackets present isobaric combinations of amino acid residues, which could not be distinguished because of the absence of the corresponding fragment ions in the mass spectrum. All peptide sequence candidates from all fragmented precursors were merged into a single MS BLAST search string. Multiple sequence candidates per each fragmented precursor were allowed. Peptides 2, 4, 5, 3 and 6 (underlined) are contained in one putative exon derived from sequence FE8.

\begin{tabular}{|c|c|c|c|c|c|c|}
\hline \# & $\mathbf{m} / \mathbf{z}$ & $\mathbf{z}$ & $\mathbf{m}$ & Sequence proposal & Alignment & Protein homologue \\
\hline \multirow[t]{3}{*}{ I } & 1185.6 & 3 & 3553.8 & SNVLYGPDTPTLSQSLGNS & Query: NVLYGPDTPTLSQS & CEACAM8 \\
\hline & & & & & NVLYGPD PT+S S & P31997 \\
\hline & & & & & Sbjct: NVLYGPDAPTISPS & H. sapiens \\
\hline \multirow[t]{3}{*}{2} & 693.3 & 3 & 2076.9 & BXXTVESVPPNAAEGKDALLR & Query: TVESVPPNAAEGKDALL & CEACAM8 \\
\hline & 1039 & 2 & & & $\mathrm{~T}+\mathrm{E}$ VP NAAEGK+ LL & P31997 \\
\hline & & & & & Sbjct: TIEAVPSNAAEGKEVLL & H. sapiens \\
\hline \multirow[t]{3}{*}{3} & 553.2 & 2 & II 04.4 & BVTTPGPAYSGR & Query: TPGPAYSGR & CEACAM8 \\
\hline & & & & & TPGPAYS R & P31997 \\
\hline & & & & & Sbjct: TPGPAYSNR & H. sapiens \\
\hline \multirow[t]{3}{*}{4} & 656.8 & 4 & 2623.2 & B [VL]LPGDTASLTWFK [W/GE/AD/SV]TVLPXXK & Query: WFKGETV & CEACAM8 \\
\hline & 875.4 & 3 & & & W+KGETV & P31997 \\
\hline & & & & & Sbjct: WYKGETV & H. sapiens \\
\hline \multirow[t]{3}{*}{5} & 539.2 & 2 & 1076.4 & BLLLYVLDTK & Query: BLLLYVLDT & Q9NOP7 \\
\hline & & & & & $+++Y V+T$ & CEA protein \\
\hline & & & & & Sbjct: RIIGYVIAT & P. hamadryas \\
\hline 6 & 425.2 & 2 & 848.4 & BFETALLR & No match & \\
\hline 7 & 386.2 & 2 & 770.4 & BTVPDSPR & No match & \\
\hline
\end{tabular}

FE8 putative exon

SLLAFWNPPTTAQVTVESVPPNAAEGKDALLRVLNLPGDTASLTWFKGETVLPTHKILLYVIDTKITTPGPAYSGRETIY

PNGSLLFQNITLNDTGSYILQIINQKFETALVRGQLQVFRE

adjusted to $20 \mathrm{mM}$ HEPES pH 7.2 and filter sterilized. Supernatant containing $1 \mathrm{mg}$ of IgG was crosslinked with dimethylpimelimidate to immobilized protein G according to supplier's recommendations (Pierce, Rockford IL).

\section{Membrane preparation}

MDCK cells were grown on plastic dishes corresponding to a surface area of $0.9 \mathrm{~m}^{2}$ equivalent to $3.6 \times 10^{9}$ cells. A postmitochondrial supernatant was obtained by homogenizing cells in $0.25 \mathrm{M}$ sucrose, $3 \mathrm{mM}$ imidazol $\mathrm{pH} 7.4$ (13× pushing through a 22-gauge needle) and centrifugation at $4,000 \times \mathrm{g}$. Membranes were pelleted for 30 minutes at $100,000 \times \mathrm{g}$, and treated on ice for 30 minutes with TNE1 (20 mM Tris pH 7.4, $150 \mathrm{mM} \mathrm{NaCl}, 5$ mM EGTA) containing $1 \% \mathrm{w} / \mathrm{v}$ Triton $\mathrm{x}-100$. Under these conditions, p58 and gp114 are efficiently solubilized. Not solubilized membranes were removed by centrifugation at 100,000 $\times$ $\mathrm{g}$ for 30 minutes, and the supernatant $(19 \mathrm{mg}$ total protein) used for immunoaffinity chromatography.

\section{WGA lectin affinity chromatography}

Solubilized membranes were adjusted to WGA buffer (10 $\mathrm{mM}$ HEPES 7.4, $1 \mathrm{mM} \mathrm{MgCl}{ }_{2}, 1 \mathrm{mM} \mathrm{CaCl}, 150 \mathrm{mM}$ $\mathrm{NaCl}, 0.1 \% \mathrm{Tx}-100)$ and circulated o/n over a $5 \mathrm{ml}$ WGAagarose (AmershamPharmacia) column at $0.2 \mathrm{ml} / \mathrm{min}$. Washing was with $10 \times$ column volume of WGA buffer, and elution in $1 \mathrm{ml}$ steps with WGA buffer containing 0.3 $\mathrm{M} \mathrm{N}$-acetylglucosamine.

\section{Immunoaffinity chromatography}

The solubilized membrane preparations were passed three times over the IgG-protein G sepharose columns. Columns were washed with $50 \mathrm{ml}$ of TNE2 $(10 \mathrm{mM}$ Tris $\mathrm{pH} 7.4,150 \mathrm{mM} \mathrm{NaCl}, 1 \mathrm{mM}$ EDTA) containing $0.1 \% \mathrm{w} /$ v Tx-100. Elution with $0.1 \mathrm{M}$ glycine $\mathrm{pH} 2.6,0.1 \% \mathrm{w} / \mathrm{v}$ Tx100 was in $1 \mathrm{ml}$ steps. Eluted fractions were neutralized, concentrated by spin columns (Centrikon YM-30), and then desalted and precipitated by methanol/chloroform extraction [28]. Aqueous supernatants were lyophilized and found to contain high amounts of gp114, but no p58. Highly glycosylated proteins have been reported to partition into the aqueous phase under these conditions [29]. 
Immunoprecipitation followed by enzymatic deglycosylation with PNGaseF (Roche) was according to standard procedures.

\section{Mass spectrometry}

Proteins separated by polyacrylamide gel electrophoresis were visualized by Coomassie staining, and bands were excised and digested by trypsin (Promega) as described [30]. $1 \mu \mathrm{l}$ aliquots of digests were analyzed by MALDI peptide mapping on a Reflex IV MALDI TOF mass spectrometer (Bruker Daltonics, Germany) using AnchorChip ${ }^{\mathrm{TM}}$ targets as described [31]. Tryptic peptides were extracted from the gel matrix by 5\% formic acid and acetonitrile, pooled and lyophilized. Peptides were sequenced by nanoelectrospray tandem mass spectrometry on a QSTAR Pulsar i quadrupole time-of-flight mass spectrometer (MDS Sciex, Canada). 40 tandem mass spectra were acquired from the digest of the gp114 band. Uninterpreted tandem mass spectra were first used to search a protein sequence database MSDB using Mascot software (Matrix Science Ltd, UK) v.1.8 installed on a local server. No restrictions on species of origin or protein molecular weight were imposed. All Mascot hits were further verified by manual inspection of matched tandem mass spectra. Spectra, which were not matched by Mascot, were manually interpreted de novo. The interpretation of each spectra rendered a few degenerate, redundant and incomplete peptide sequence candidates, which were assembled into a single MS BLAST [9] query string as described previously [32]. MS BLAST searches against the non-redundant protein database nrdb95 were performed on a web server [33].

\section{In silico analysis}

The human CD66a sequence was blasted against a dog genomic database [34]. The best match was obtained with sequence G630P617675FE8.T0, which was then translated into the amino acid sequence. After the dog genome became available, we repeated our homology searches. Since the FE8 data showed that four of the sequenced peptides (\#2-\#4-\#5-\#3) form an almost continuous stretch, we could probe the new (nucleotide) databases now with a 65 amino acid sequence. Eight significant alignments were found, all on chromosome I. The top three alignments were investigated more closely (exclusion limit: better than $90 \%$ over 60 amino acids, taking into account that MS cannot distinguish between Ile and Leu or isobaric amino acid combinations). Only one translated nucleotide sequence contained peptides \#1 and \#6. Using human CEACAM family proteins for guidance, a tentative amino acid surfaced out of merging putative exons. This sequence was $58-61 \%$ identical and $67-71 \%$ similar to human CEACAM family proteins $1,5,8$ and 6 .

\section{Abbreviations \\ CEA, carcinoembryonic antigen}

CEACAM, carcinoembryonic antigen-related cell adhesion molecule

MDCK, Madin-Darby canine kidney

WGA, wheat germ agglutinin

\section{Authors' contributions}

J. F. initiated and designed the study, did all biochemical work and wrote the manuscript. Anna S. did the mass spectrometry analysis, Andrej S. and K. S. co-wrote the manuscript.

\section{Acknowledgements}

Antibodies against canine ICAM-I were kindly provided by $C$. Wayne Smith (BCM, Houston, USA). This study was supported by grants SFB-TRI3-

TPAI and HPRN-CT-2002-00259 to K.S.

\section{References}

I. Rodriguez-Boulan E, Nelson WJ: Morphogenesis of the polarized epithelial cell phenotype. Science 1989, 245(49/9):7|8-725.

2. Nelson W]: Adaptation of core mechanisms to generate cell polarity. Nature 2003, 422(6933):766-774.

3. Ikonen E, Simons K: Protein and lipid sorting from the transGolgi network to the plasma membrane in polarized cells. Semin Cell Dev Biol 1998, 9(5):503-509.

4. Balcarova-Stander J, Pfeiffer SE, Fuller SD, Simons K: Development of cell surface polarity in the epithelial Madin-Darby canine kidney (MDCK) cell line. Embo J 1984, 3( I I):2687-2694.

5. Sambuy Y, Rodriguez-Boulan E: Isolation and characterization of the apical surface of polarized Madin-Darby canine kidney epithelial cells. Proc Natl Acad Sci USA 1988, 85(5): I 529-1533.

6. Aebersold R, Mann M: Mass spectrometry-based proteomics. Nature 2003, 422(6928): 198-207.

7. Liska AJ, Shevchenko A: Expanding organismal scope of proteomics: cross-species protein identification by mass spectrometry and its implications. Proteomics 2003, 3(I): 19-28.

8. Sunyaev S, Liska AJ, Golod A, Shevchenko A, Shevchenko A: MultiTag: multiple error-tolerant sequence tag search for the sequence-similarity identification of proteins by mass spectrometry. Anal Chem 2003, 75:1307-I3/5.

9. Shevchenko A, Sunyaev S, Loboda A, Shevchenko A, Bork P, Ens W, Standing K: Charting the proteomes of organisms with unsequenced genomes by MALDI-Quadrupole Time-of-Flight mass spectrometry and BLAST homology searching. Anal Chem 200I, 73:1917-1926.

10. Habermann B, Oegema J, Sunyaev S, Shevchenko A: The power and the limitations of cross-species protein identification by mass spectrometry-driven sequence similarity searches. Mol Cell Proteomics 2004, 3(3):238-249.

II. Shevchenko A, Loboda A, Ens W, Schraven B, Standing KG, Shevchenko A: Archived polyarylamide gels as a resource for proteome characterization by mass spectrometry. Electrophoresis 200I, 22: I 194-I203.

12. Shevchenko A, Chernushevic I, Wilm M, Mann M: "De novo" sequencing of peptides recovered from in-gel digested proteins by nanoelectrospray tandem mass spectrometry. Mol Biotechnol 2002, 20(I): 107-I 18.

13. Liska AJ, Popov AV, Sunyaev S, Coughlin P, Habermann B, Shevchenko A, Bork P, Karsenti E: Homology-based functional proteomics by mass spectrometry: application to the Xenopus microtubule-associated proteome. Proteomics 2004, 4(9):2707-2721.

14. Obrink B: CEA adhesion molecules: multifunctional proteins with signal-regulatory properties. Curr Opin Cell Biol 1997, 9(5):616-626 
15. Hammarstrom S: The carcinoembryonic antigen (CEA) family: structures, suggested functions and expression in normal and malignant tissues. Semin Cancer Biol 1999, 9(2):67-8I.

16. Le Bivic A, Sambuy Y, Mostov K, Rodriguez-Boulan E: Vectorial targeting of an endogenous apical membrane sialoglycoprotein and uvomorulin in MDCK cells. I Cell Biol 1990, I I0(5): I533-I539.

17. Lindblad-Toh K, Wade CM, Mikkelsen TS, Karlsson EK, Jaffe DB, Kamal M, Clamp M, Chang JL, Kulbokas EJ 3rd, Zody MC, et al.: Genome sequence, comparative analysis and haplotype structure of the domestic dog. Nature 2005, 438(7069):803-819.

18. Le Bivic A, Garcia M, Rodriguez-Boulan E: Ricin-resistant MadinDarby canine kidney cells missort a major endogenous apical sialoglycoprotein. J Biol Chem 1993, 268(10):6909-69|6.

19. Beauchemin N, Draber P, Dveksler G, Gold P, Gray-Owen S, Grunert F, Hammarstrom S, Holmes KV, Karlsson A, Kuroki M, et al.: Redefined nomenclature for members of the carcinoembryonic antigen family. Exp Cell Res 1999, 252(2):243-249.

20. Meiss HK, Green RF, Rodriguez-Boulan EJ: Lectin-resistant mutants of polarized epithelial cells. Mol Cell Biol 1982, 2(10): 1287-1294.

21. Brandli AW, Hansson GC, Rodriguez-Boulan E, Simons K: A polarized epithelial cell mutant deficient in translocation of UDPgalactose into the Golgi complex. J Biol Chem 1988, 263(3I): 16283-16290.

22. Brandli AW, Parton RG, Simons K: Transcytosis in MDCK cells: identification of glycoproteins transported bidirectionally between both plasma membrane domains. J Cell Biol 1990, I II (6 Pt 2):2909-292I.

23. Verkade $P$, Harder T, Lafont F, Simons K: Induction of caveolae in the apical plasma membrane of Madin-Darby canine kidney cells. J Cell Biol 2000, I 48(4):727-739.

24. Simons K, Toomre D: Lipid rafts and signal transduction. Nat Rev Mol Cell Biol 2000, I(I):3I-39.

25. Dunbar LA, Caplan MJ: The cell biology of ion pumps: sorting and regulation. Eur J Cell Biol 2000, 79(8):557-563.

26. Shoshani L, Contreras RG, Roldan ML, Moreno J, Lazaro A, Balda MS, Matter K, Cereijido M: The Polarized Expression of $\mathbf{N a +}, \mathbf{K +}$ ATPase in Epithelia Depends on the Association between \{beta\}-Subunits Located in Neighboring Cells. Mol Biol Cell 2005, 16(3): 107|-1081.

27. Liska AJ, Shevchenko A: Combining mass spectrometry with database interrogation strategies in proteomics. Trends Anal Chem 2003, 22:291-298.

28. Wessel D, Flugge UI: A method for the quantitative recovery of protein in dilute solution in the presence of detergents and lipids. Anal Biochem 1984, I38(I): I4I-I43.

29. Schmidt K, Dartsch H, Linder D, Kern H, Kleene R: A submembranous matrix of proteoglycans on zymogen granule membranes is involved in granule formation in rat pancreatic acinar cells. J Cell Sci 2000, I I 3( I 2):2233-2242.

30. Shevchenko A, Wilm M, Vorm O, Mann M: Mass spectrometric sequencing of proteins from silver-stained polyacrylamide gels. Anal Chem 1996, 68(5):850-858.

31. Havlis J, Thomas H, Sebela M, Shevchenko A: Fast responce proteomics by accelerated in-gel digestion of proteins. Anal Chem 2003, 75: 1300-1306.

32. Shevchenko A, Sunyaev S, Liska A, Bork P, Shevchenko A: Nanoelectrospray tandem mass spectrometry and sequence similarity searching for identification of proteins from organisms with unknown genomes. Meth Mol Biol 2002, 2 I I:22I-234.

33. MS BLAST Search at EMBL [http://dove.embl-heidelberg.de/ Blast $2 / \mathrm{msblast} . \mathrm{html}]$

34. Trace Archive database Mega BLAST search [http:// www.ncbi.nlm.nih.gov/BLAST/mmtrace.shtml]
Publish with Biomed Central and every scientist can read your work free of charge

"BioMed Central will be the most significant development for disseminating the results of biomedical research in our lifetime. "

Sir Paul Nurse, Cancer Research UK

Your research papers will be:

- available free of charge to the entire biomedical community

- peer reviewed and published immediately upon acceptance

- cited in PubMed and archived on PubMed Central

- yours - you keep the copyright

Submit your manuscript here:

http://www.biomedcentral.com/info/publishing_adv.asp
BioMedcentral 